\title{
Electrochemical Study of Esculetin Nitration by Digital Simulation of Cyclic Voltammograms
}

\author{
Lida Khalafi, ${ }^{1}$ Mohammad Yari, ${ }^{2}$ Farzaneh Yadaei, ${ }^{3}$ and Shabnam Majidzade ${ }^{1}$ \\ ${ }^{1}$ Department of Chemistry, Shahr-e-Qods Branch, Islamic Azad University, Tehran, Iran \\ ${ }^{2}$ Department of Chemistry, Islamic Azad University, Islamshahr Branch, Tehran, Iran \\ ${ }^{3}$ Department of Chemistry, Islamic Azad University, Saveh Branch, Saveh, Iran
}

Correspondence should be addressed to Lida Khalafi; 1_khalafi@yahoo.com

Received 2 December 2011; Revised 17 May 2012; Accepted 27 May 2012

Academic Editor: Beatriz Oliveira

Copyright (C) 2013 Lida Khalafi et al. This is an open access article distributed under the Creative Commons Attribution License, which permits unrestricted use, distribution, and reproduction in any medium, provided the original work is properly cited.

\begin{abstract}
The reaction of electrochemically generated $o$-quinones from oxidation of esculetin as Michael acceptor with nitrite ion as nucleophile has been studied using cyclic voltammetry. The reaction mechanism is believed to be EC, including oxidation of catechol moiety of esculetin followed by Michael addition of nitrite ion. The observed homogeneous rate constants $\left(k_{\text {obs }}\right)$ for reactions were estimated by comparing the experimental voltammetric responses with the digitally simulated results based on the proposed mechanism. Also the effects of $\mathrm{pH}$ and nucleophile concentration on voltammetric behavior and the rate constants of chemical reactions were described.
\end{abstract}

\section{Introduction}

Coumarins are an important group of organic compounds that are made of fused benzene and $\alpha$-pyrone rings. Numerous studies reveal that these compounds have interesting pharmacological and biochemical properties [1-3]. Esculetin is a coumarin derivative contained in many plants, such as Citrus limonia and Euphorbia lathyris. It has multiple biological activities, including the inhibition of the xanthine oxidize activity [4], platelet aggregation [5], and the induction apoptosis. In addition, esculetin shows antioxidative activity $[6,7]$, an inhibitory effect on the growth of human breast cancer [8]. Molecular electrochemistry studies the mechanistic events at or near an electrode on a molecular level, and voltammetry is convenient and the most frequently used technique for this purpose [9]. Esculetin has a catechol skeleton in its structure, and electrochemical experiments show that the first oxidation of this compound is related to the oxidation of its catechol group [10]. Oxidation of catechol derivatives occurs at very low positive potentials, and the product of oxidation is $o$-quinone. Electrogenerated $o$ quinone is a highly reactive species, which undergoes various following chemical reactions [11]. The aim of this work is the kinetic study of esculetin oxidation in the presence of nitrite ion and possibility of its nitration through electrochemical activation.

\section{Experimental}

2.1. Apparatus. Cyclic voltammetry was performed using a Behpajoh Model BHP 2061-C potentiostat/galvanostat. In the voltammetry experiments a glassy carbon disc $(2 \mathrm{~mm}$ diameter) and a platinum wire were used as working and counterelectrodes, respectively. The working electrode potentials were measured versus $\mathrm{Ag} / \mathrm{AgCl}(\mathrm{KCl} 3.0 \mathrm{M})$, all electrodes (working, reference, and counter) from AZAR electrode (Urmia, Iran).

2.2. Reagents and Solutions. All of the experiments were performed with analytical-reagent-grade chemicals purchased from E. Merck. These chemicals were used without further purification. The stock solutions of the esculetin and sodium nitrite were prepared fresh daily by dissolving the compounds in acetonitrile/water, 20/80, and distilled water, respectively. Samples were prepared by taking the appropriate aliquots from the stock solutions followed by dilution with buffer solutions, $\mathrm{pHs} 5.0,6.0,6.5$, and 7.0 . The $0.15 \mathrm{M}$ buffered 


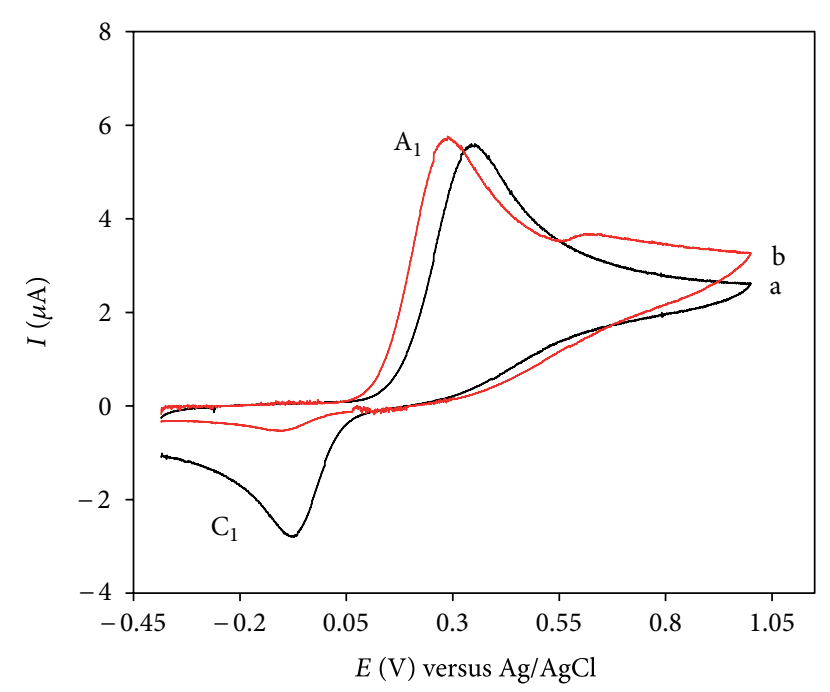

FIgURE 1: Cyclic voltammograms of $1.0 \mathrm{mM}$ esculetin: (a) in the absence and (b) the presence of $5.0 \mathrm{mM}$ nitrite ion, at glassy carbon electrode, in acetonitrile/water solution containing phosphate buffer $(\mathrm{pH}=6.0, c=0.15 \mathrm{M})$. Scan rate $20 \mathrm{mV} \mathrm{s}^{-1}$.

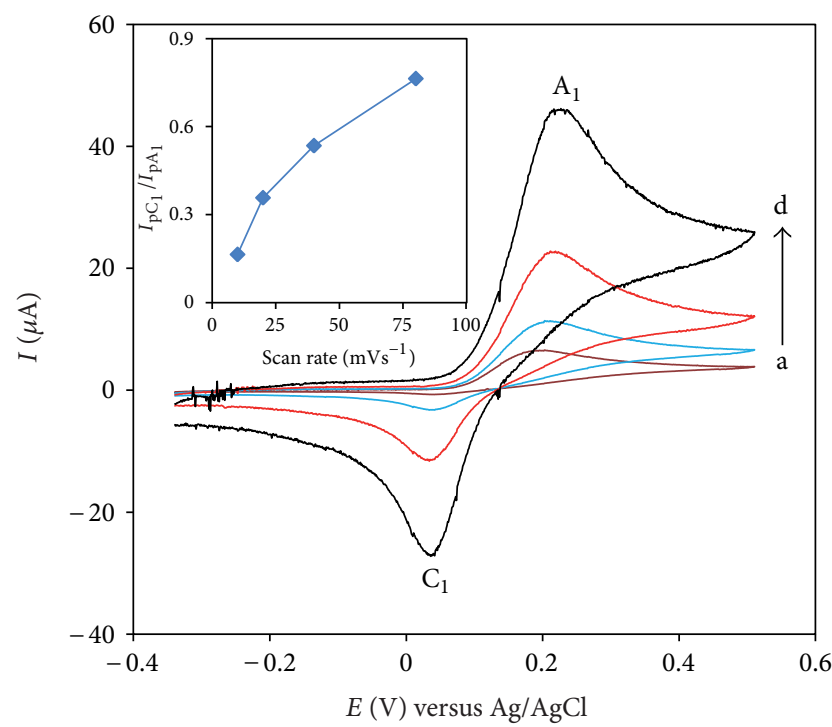

Figure 2: Cyclic voltammograms of $1.0 \mathrm{mM}$ esculetin in the presence of $5.0 \mathrm{mM}$ nitrite ion, at a glassy carbon electrode, in phosphate buffer solution $(\mathrm{pH}=6.0, c=0.15 \mathrm{M})$. Scan rates from (a) to (d) are $10,20,40$, and $80 \mathrm{mVs}^{-1}$, respectively. Inset: variation of cathodic-to anodic-peak current ratios versus scan rate.

solutions were prepared based on Kolthoff's tables [12]. The homogeneous rate constants were estimated by analyzing the cyclic voltammetric responses using the simulation CVSIM software [13].

\section{Results and Discussion}

3.1. Voltammetric Study. Figure 1, curve a, shows the cyclic voltammogram of $1.0 \mathrm{mM}$ esculetin in the absence of nitrite

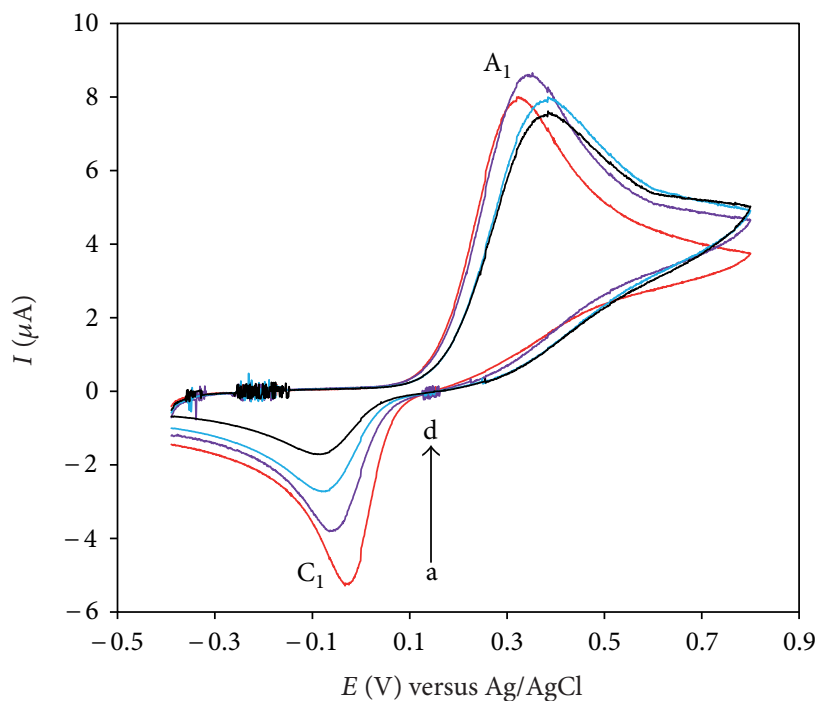

Figure 3: Cyclic voltammograms of $1.0 \mathrm{mM}$ esculetin in the presence of different concentrations of nitrite ion, $\mathrm{pH}=6.0$. Concentrations from (a) to (d) are 1.0, 3.0, 5.0, and 10.0 mM. Scan rate: $40 \mathrm{mV} \mathrm{s}^{-1}$.

ion at $\mathrm{pH} 6.0$ in the mixture of acetonitrile/water solution. The cyclic voltammogram of esculetin shows one anodic $\left(\mathrm{A}_{1}\right)$ and corresponding cathodic peaks $\left(\mathrm{C}_{1}\right)$ with peak current ratio near but less than unity, within two-electron process. The electrode response of esculetin can be related to the transformation of its catechol group to $o$-quinone and vice versa [10].

Figure 1, curve b, shows cyclic voltammogram of $1.0 \mathrm{mM}$ esculetin in the presence of $5.0 \mathrm{mM}$ nitrite ion in the same solution. In this condition, the most important difference between the voltammograms in the presence and absence of nitrite ion is the decrease of the magnitude of cathodic peak $\left(\mathrm{C}_{1}\right)$ currents. As mentioned above the height of $\mathrm{C}_{1}$ peak is proportional to the amount of produced $o$-quinone. Decrease in the $C_{1}$ peak currents is indicative of this fact that the oxidized intermediate formed at the surface of electrode is removed by a chemical reaction during the voltammetric experiment. The time scale of a voltammetric experiment is determined by the scan rate. It is an important parameter in the study of homogeneous reactions coupled with electrode reactions [14]. Figure 2 shows the effect of potential scan rate on voltammograms of esculetin in the presence of nitrite ion at $\mathrm{pH}$ 6.0. It shows that by augmentation of scan rate the height of both anodic and cathodic peaks increases, but the increase in $\mathrm{C}_{1}$ height is more than expected for simple electrode reaction. On the other hand, the anodicto-cathodic peaks current ratio rises parallel to the increase in scan rate. This is reflected by the low extent of chemical reaction at the period of recording the cyclic voltammograms at high scan rates. Inset of Figure 2 shows the peak current ratio $\left(I_{\mathrm{pA}} / I_{\mathrm{pC}}\right)$ versus scan rate for a mixture of esculetin and nitrite ion.

Also the voltammetric studies were performed at various concentrations of nitrite ion (Figure 3). By increasing the concentration of nitrite ion, the height of cathodic peaks and 


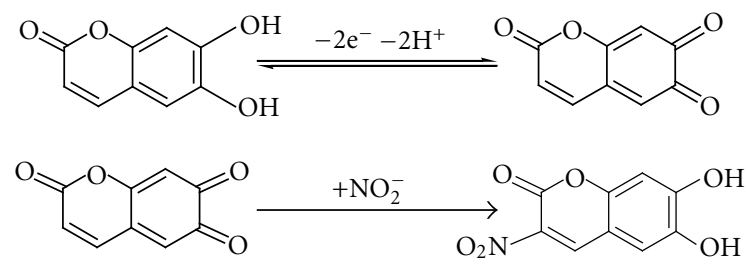

SCHEME 1

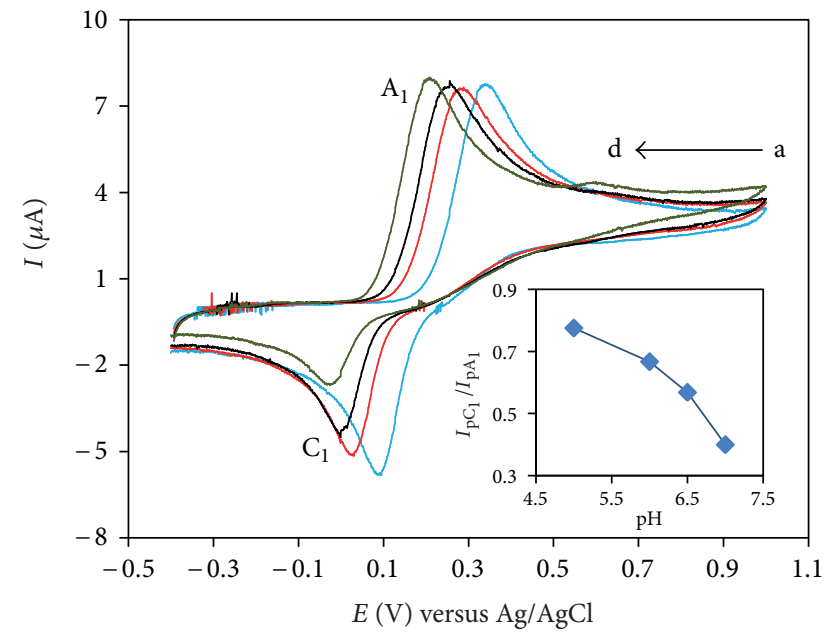

FIgURE 4: Cyclic voltammograms of $1.0 \mathrm{mM}$ esculetin in the presence of $1.0 \mathrm{mM}$ nitrite ion at various $\mathrm{pH}$ values (a) 5.0 , (b) 6.0 , (c) 6.5 and (d) 7.0. Scan rate: $40 \mathrm{mV} \mathrm{s}^{-1}$. Inset: variation of cathodicto-anodic peak current ratios versus $\mathrm{pH}$.

their ratio over the $A_{1}$ peak are decreased. This is a good criterion for more extent of chemical reaction of $o$-quinone in the presence of higher concentrations of nitrite ion.

Such behaviors are good criteria for EC mechanism consisting of an electron transfer reaction $(E)$ followed by a chemical reaction $(C)$ [14]. According to these results, electrochemical oxidation of esculetin causes formation of related $o$-quinone that undergoes Michael addition reaction with nitrite ion. It is faster than other secondary reactions and leads to the related nitroderivatives. The oxidation of the product is more difficult than the oxidation of parent molecule and is prevented by virtue of the presence of the electron-withdrawing nitrogroup on catechol ring [15]. As shown in Figure 1, a new anodic peak, with more positive peak potential, may be related to the oxidation of the product. The proposed reaction pathway is shown in Scheme 1.

Because of the $\mathrm{pH}$ dependence of esculetin oxidation and the possibility of $\mathrm{pH}$ dependence of the Michael addition, voltammetric studies have been performed at various $\mathrm{pHs}$ values (Figure 4).

In basic solutions, the height of esculetin reduction peak decreases due to some considerable side reactions. They consist of the intramolecular reaction of hydroxy groups and coupling of anionic forms of esculetin with $o$-quinones. But the peak current ratio near unity at neutral and acidic
TABLE 1: Homogeneous rate constants $\left(k_{\mathrm{obs}}\right)$ for esculetin at various pHs.

\begin{tabular}{lcccc}
\hline $\mathrm{pH}$ & 5.0 & 6.0 & 6.5 & 7.0 \\
$k_{\mathrm{obs}}\left(\mathrm{s}^{-1}\right)^{*}$ & 0.0040 & 0.005 & 0.007 & 0.01 \\
\hline
\end{tabular}

The observed rate constants in the presence of $1.0 \mathrm{mM}$ nitrite ion.

solutions can be considered as relative stability of the $o$ quinone [16]. Therefore, the effect of $\mathrm{pH}$ has been studied at pHs lower than 7.0. At the desired neutral and mild acidic solutions and presence of nitrite ion, the peak current ratio is less than unity and decreases with increasing $\mathrm{pH}$. The plot of the current peak ratio versus solution $\mathrm{pH}$ is shown in the inset of Figure 4. Nitrite ion is a weak base, and variations of reaction rates with $\mathrm{pH}$ are due to protonation of nitrite ion and variation of its percentage $[12,17]$.

3.2. Kinetic Evaluation. The scheme for the electrochemical oxidation of esculetin in the presence of nitrite ion was proposed and tested by diagnostic criteria of cyclic voltammograms. One of the successful methods for obtaining kinetic parameters of the coupled homogeneous reaction is digital simulation [18]. The simulation was carried out based on the proposed EC mechanism and assuming semiinfinite one-dimensional diffusion on a planar electrode. The experimental parameters entered for digital simulation consist of the following: starting potential $\left(E_{\text {start }}\right)$, switching potential $\left(E_{\text {switch }}\right)$, scan rate $(\mathrm{v})$, half wave potential $\left(E_{1 / 2}\right)$ and analytical concentration of species. The formal potentials were obtained experimentally as midpoint potential between the anodic and cathodic peaks (Emid). The transfer coefficients $(\alpha)$ and heterogeneous rate constants for oxidation of esculetin were estimated by experimental working curves $[19,20]$. All these parameters were kept constant, and the observed rate constant of chemical reaction $k_{\text {obs }}$ was allowed to change during the fitting processes. The fitting consists of finding a rate constant for which the differences between the digitally simulated and the experimental data reach the minimum [17]. The rate constant of the reaction of the produced quinone from oxidation of esculetin with nitrite ion was estimated for various $\mathrm{pHs}$, nitrite ion concentrations, and scan rates. As shown in Figure 5, there are good agreements between the simulated voltammograms and those obtained experimentally.

The observed rate constants of the coupling reaction of oxidized esculetin with nitrite ion at various $\mathrm{pHs}$ are presented in Table 1. Based on these results the rate of 


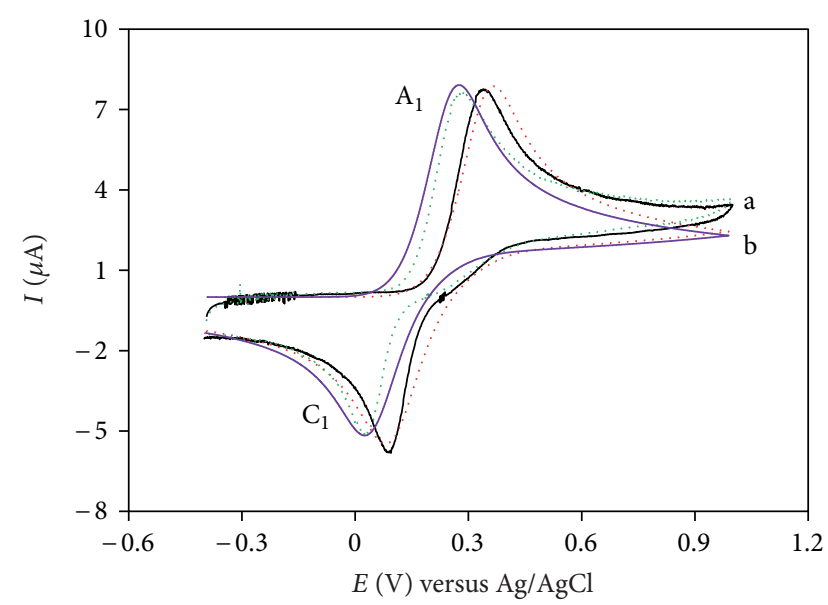

(A)

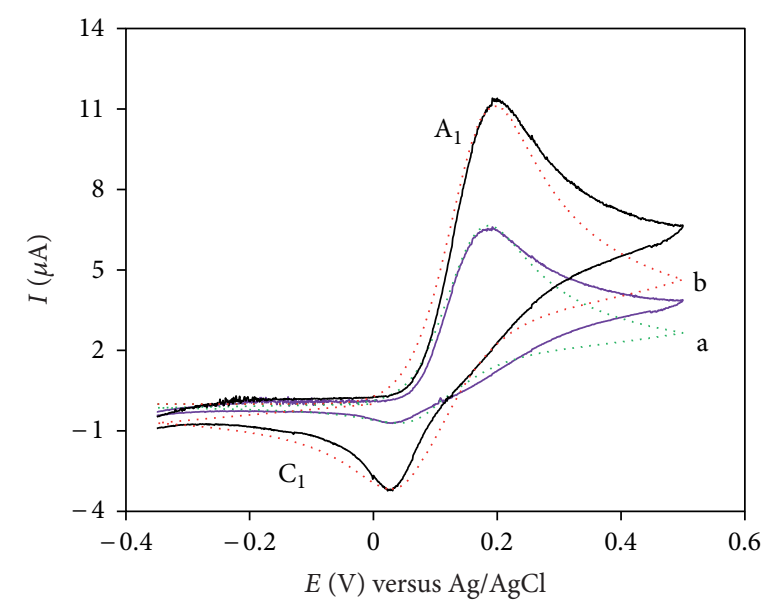

(B)

FIGURE 5: Simulated (doted) and experimental (line) cyclic voltammograms of esculetin in the presence of nitrite ion at $(\mathrm{A})(\mathrm{a}) \mathrm{pH}=5.0,(\mathrm{~b})$ $\mathrm{pH}=6.0$ (B) various scan rate; (a) 10 , (b) $20 \mathrm{mVs}^{-1}$.

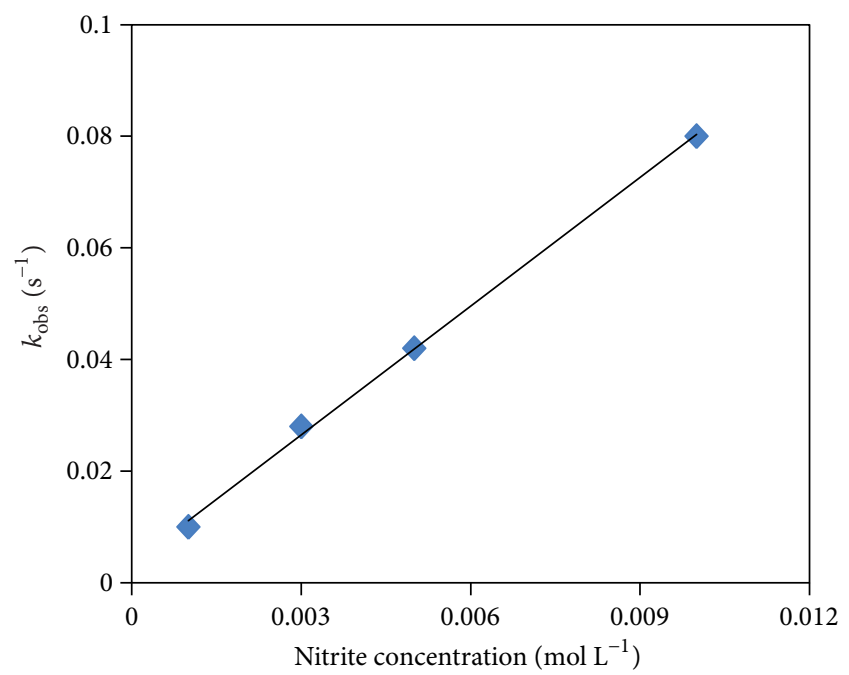

Figure 6: The plot of the observed rate constants of Michael addition $\left(k_{\text {obs }}\right)$ versus nitrite ion concentration at $\mathrm{pH} 5$.

reaction enhances at high $\mathrm{pH}$ values, which are related to increasing the nitrite ion percentages.

Also the observed rate constants of reactions were obtained by digital simulation at various concentrations of nitrite ion. Figure 6 shows the plots of $k_{\text {obs }}$ as a function of nitrite ion concentration.

The results of simulation at various concentrations of nitrite ion show that the observed rate constants $\left(k_{\text {obs }}\right)$ increase linearly as a function of nitrite ion concentrations, which is expected based on voltammetric results. Since $k_{\mathrm{obs}}=$ $k\left[\mathrm{NO}_{2}{ }^{-}\right]$, where $k$ is the rate constant of reaction, the value of rate constant can be obtained from the slope of the plot in Figure 6. The values of the obtained rate constants (k) at $\mathrm{pH} 6.0$ are $7.7 \mathrm{M}^{-1} \mathrm{~s}^{-1}$ for esculetin. The standard deviations were obtained less than $10 \%$ for independent simulations at various conditions. For example, it is $8.9 \%$ for four simulations at different scan rates. The rate constant of nitration is considerable at this mild condition. The nitration of aromatic compounds is mostly performed based on their nucleophilicity [21]. However, in this work, we investigate nitration of esculetin based on electrophilicity of electrochemically generated $o$-quinone. The possibility of in situ generation of reactive intermediates and inversion in polarity by transfer of electron at the electrode solution interface has been found considerable attention in various areas of chemistry.

\section{Conclusion}

The results of this work show that esculetin is converted to the respective nitro derivative at very mild conditions. The reaction mechanism is formation of reactive $o$-quinone as the product of two electron oxidation of esculetin and nucleophilic attack of nitrite ion via a Michael addition reaction. It is a good example of in-situ generation of reactive species by electrochemical methods. Proposed mechanism and presence of coupled homogeneous reaction was supported by the analysis of voltammetric responses and diagnostic criteria of cyclic voltammograms. Also the homogeneous rate constant of nitration reaction was obtained based on digital simulation at various conditions. Based on these results the rate of nitration reaction enhance by increasing $\mathrm{pH}$ and nitrite ion concentration. The observed rate of nitration has a linear dependence to nitrite ion concentration and the overall reaction order is 1 with respect to $\left[\mathrm{NO}_{2}{ }^{-}\right]$.

\section{References}

[1] D. Bogdal, "Coumarins: fast synthesis by knoevenagel condensation under microwave irradiation," Journal of Chemical Research, no. 8, pp. 468-469, 1998.

[2] L. Muschietti, S. Gorzalczany, G. Ferraro, C. Acevedo, and V. Martino, "Phenolic compounds with anti-inflammatory activity 
from Eupatorium buniifolium," Planta Medica, vol. 67, no. 8, pp. 743-744, 2001.

[3] T. Neichi, Y. Koshihara, and S. I. Murota, "Inhibitory effect of esculetin on 5-lipoxygenase and leukotriene biosynthesis," Biochimica et Biophysica Acta, vol. 753, no. 1, pp. 130-132, 1983.

[4] D. Egan, R. O’Kennedy, E. Moran, D. Cox, E. Prosser, and R. D. Thornes, "The pharmacology, metabolism, analysis, and applications of coumarin and coumarin-related compounds," Drug Metabolism Reviews, vol. 22, no. 5, pp. 503-529, 1990.

[5] Y. Okada, N. Miyauchi, K. Suzuki et al., "Search for naturally occurring substances to prevent the complications of diabetes. II. Inhibitory effect of coumarin and flavonoid derivatives on bovine lens aldose reductase and rabbit platelet aggregation," Chemical and Pharmaceutical Bulletin, vol. 43, no. 8, pp. 1385-1387, 1995.

[6] M. Paya, B. Halliwell, and J. R. S. Hoult, "Interactions of a series of coumarins with reactive oxygen species. Scavening of superoxide, hypochlorous acid and hydroxyl radicals," Biochemical Pharmacology, vol. 44, no. 2, pp. 205-214, 1992.

[7] W.-L. Lin, C.-J. Wang, Y.-Y. Tsai, C.-L. Liu, J.-M. Hwang, and T.-H. Tseng, "Inhibitory effect of esculetin on oxidative damage induced by t-butyl hydroperoxide in rat liver," Archives of Toxicology, vol. 74, no. 8, pp. 467-472, 2000.

[8] M. Noguchi, M. Earashi, M. Minami, I. Miyazaki, M. Tanaka, and T. Sasaki, "Effects of piroxicam and esculetin on the MDA-MB-231 human breast cancer cell line," Prostaglandins Leukotrienes and Essential Fatty Acids, vol. 53, no. 5, pp. 325-329, 1995.

[9] J. M. Saveant, Elements of Molecular and Biomolecular Electrochemistry, Willey-VCH, NJ, USA, 2006.

[10] H. Salehzadeh, D. Nematollahi, and M. Rafiee, "Electrochemical dimerization of 4-methylesculetin: synthesis and kinetic study of a highly-oxygenated dimer," Journal of Electroanalytical Chemistry, vol. 650, no. 2, pp. 226-232, 2011.

[11] A. Afkham, D. Nematollahi, L. Khalafi, and M. Rafiee, "Kinetic study of the oxidation of some catecholamines by digital simulation of cyclic voltammograms," International Journal of Chemical Kinetics, vol. 37, no. 1, pp. 17-24, 2005.

[12] I. M. Kolthoff, E. B. Sandel, and E. J. Meehan, Quantitative Chemical Analysis, Macmillan, London, UK, 4th edition, 1971.

[13] D. K. Gosser, Cyclic Voltammetry: Simulation and Analysis of Reaction Mechanisms, VCH, New York, NY, USA, 1993.

[14] D. Nematollahi, M. Rafiee, and L. Fotouhi, "Mechanistic study of homogeneous reactions coupled with electrochemical oxidation of catechols," Journal of the Iranian Chemical Society, vol. 6 , no. 3, pp. 448-476, 2009.

[15] D. Nematollahi, A. Ariapad, and M. Rafiee, "Electrochemical nitration of catechols: kinetic study by digital simulation of cyclic voltammograms," Journal of Electroanalytical Chemistry, vol. 602, no. 1, pp. 37-42, 2007.

[16] L. Khalafi, M. Rafiee, and F. Yadaei, "Voltammetric study of the oxidation of quercetin and catechin in the presence of cyanide ion," Research on Chemical Intermediates, vol. 37, no. 8, pp. 1047-1055, 2011.

[17] L. Khalafi and M. Rafiee, "Kinetic study of the oxidation and nitration of catechols in the presence of nitrous acid ionization equilibria," Journal of Hazardous Materials, vol. 174, no. 1-3, pp. 801-806, 2010.

[18] D. Britz, Digital Simulation in Electrochemistry, Springer, Berlin, Germany, 2005.
[19] D. Nematollahi, A. Afkhami, F. Mosaed, and M. Rafiee, "Investigation of the electro-oxidation and oxidation of catechol in the presence of sulfanilic acid," Research on Chemical Intermediates, vol. 30, no. 3, pp. 299-309, 2004.

[20] A. J. Bard and L. R. Faulkner, Electrochemical Methods, Wiley \& Sons, New York, NY, USA, 2nd edition, 2001.

[21] F. A. Carey and R. J. Sundberg, Advanced Organic Chemistry, Part B, Plenum, New York, NY, USA, 2001. 

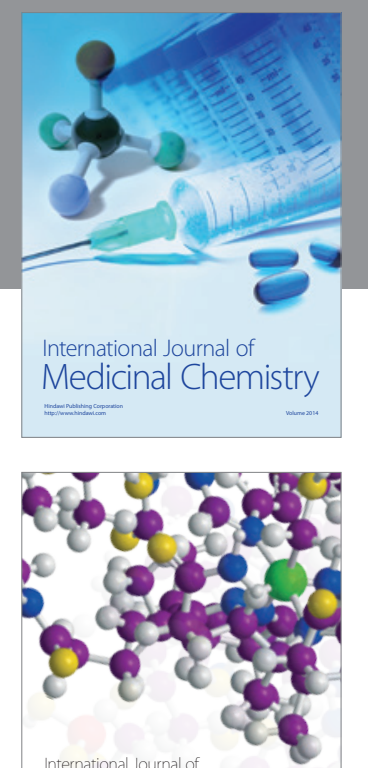

\section{Carbohydrate} Chemistry

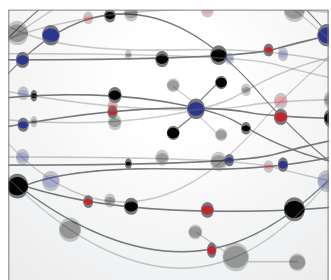

The Scientific World Journal
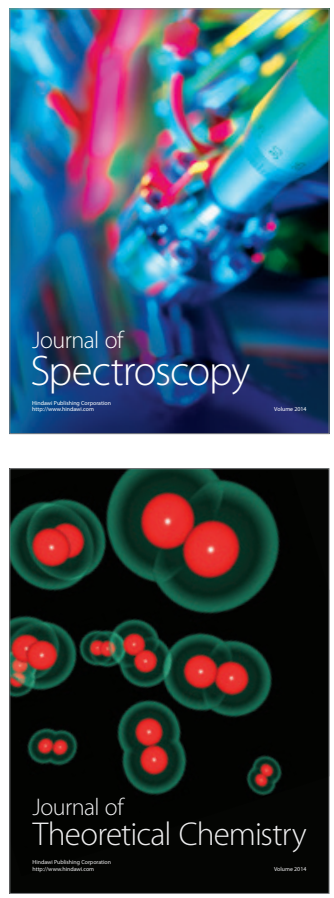
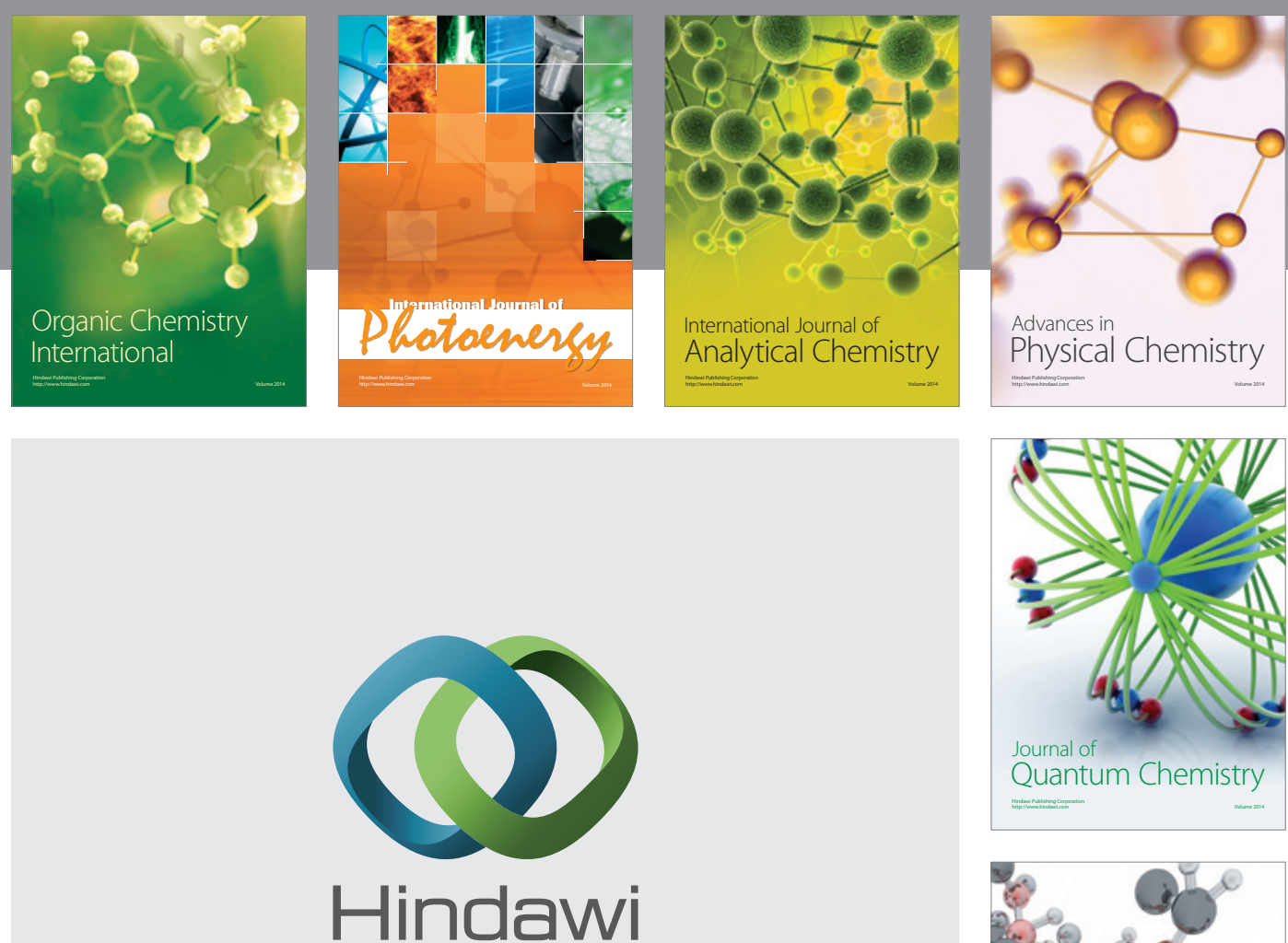

Submit your manuscripts at

http://www.hindawi.com

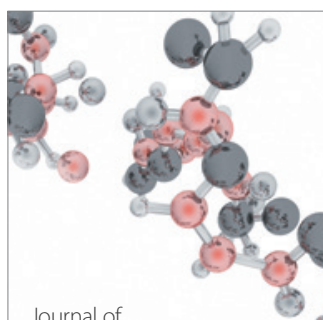

Analytical Methods

in Chemistry

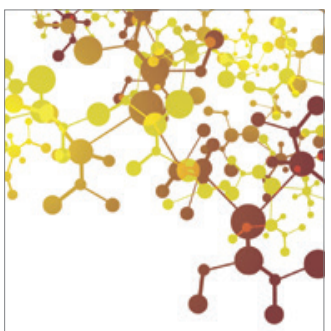

Journal of

Applied Chemistry

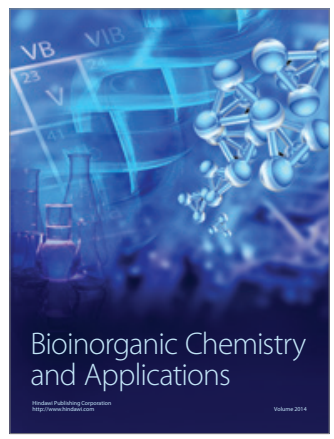

Inorganic Chemistry
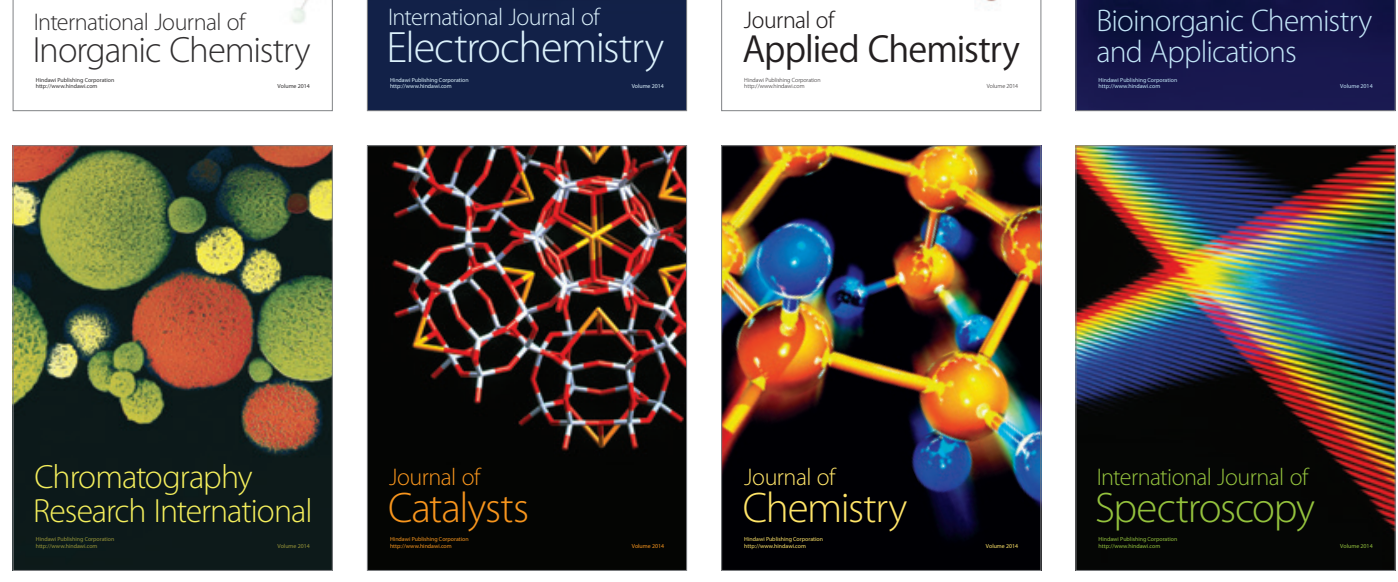